\title{
Choosing and Doing wisely: triage level I resuscitation a possible new field for starting palliative care and avoiding low- value care - a nationwide matched-pair retrospective cohort study in Taiwan
}

Chih-Yuan Lin ${ }^{1,2,3}$ and Yue-Chune Lee ${ }^{2,4^{*}}$

\begin{abstract}
Background: The association between palliative care and life-sustaining treatment following emergency department (ED) resuscitation is unclear. This study aims to analyze the usage of palliative care and life-sustaining treatments among ED triage level I resuscitation patients based on a nationally representative sample of patients in Taiwan.

Methods: A matched-pair retrospective cohort study was conducted to examine the association between palliative care and outcome variables using multivariate logistic regression and Kaplan-Meier survival analyses. Between 2009 and 2013, 336 ED triage level I resuscitation patients received palliative care services (palliative care group) under a universal health insurance scheme. Retrospective cohort matching was performed with those who received standard care at a ratio of 1:4 (usual care group). Outcome variables included the number of visits to emergency and outpatient departments, hospitalization duration, total medical expenses, utilization of life-sustaining treatments, and duration of survival following ED triage level I resuscitation.

Results: The mean survival duration following level I resuscitation was less than 1 year. Palliative care was administered to $15 \%$ of the resuscitation cohort. The palliative care group received significantly less life-sustaining treatment than did the usual care group.

Conclusion: Among patients who underwent level I resuscitation, palliative care was inversely correlated with the scope of life-sustaining treatments. Furthermore, triage level I resuscitation status may present a possible new field for starting palliative care intervention and reducing low-value care.
\end{abstract}

Keywords: Emergency care, Triage, Resuscitation, Palliative care, Life-sustaining treatment, Advance care planning, Advanced decision

\footnotetext{
* Correspondence: yclee@ym.edu.tw

${ }^{2}$ Institute of Health and Welfare Policy, School of Medicine, National Yang-Ming University, Taipei, Taiwan

${ }^{4}$ Master Program on Trans-disciplinary Long-Term Care and Management, National Yang-Ming University, Taipei, Taiwan

Full list of author information is available at the end of the article
}

(c) The Author(s). 2020 Open Access This article is licensed under a Creative Commons Attribution 4.0 International License, which permits use, sharing, adaptation, distribution and reproduction in any medium or format, as long as you give appropriate credit to the original author(s) and the source, provide a link to the Creative Commons licence, and indicate if changes were made. The images or other third party material in this article are included in the article's Creative Commons licence, unless indicated otherwise in a credit line to the material. If material is not included in the article's Creative Commons licence and your intended use is not permitted by statutory regulation or exceeds the permitted use, you will need to obtain permission directly from the copyright holder. To view a copy of this licence, visit http://creativecommons.org/licenses/by/4.0/ The Creative Commons Public Domain Dedication waiver (http://creativecommons.org/publicdomain/zero/1.0/) applies to the data made available in this article, unless otherwise stated in a credit line to the data. 


\section{Background}

Emergency department (ED) resuscitation refers to a critical time-sensitive state requiring immediate resuscitation $[1,2]$. The fundamental task of critical care is to initiate timely stabilization, diagnosis, and therapeutic interventions to save a patient's life and improve their prognosis. The constant updating of evidence-based resuscitation, advanced life support, and rapid development of organ replacement life-sustaining treatments have led to better progress in resuscitation practices. However, the inevitability of end-of-life situations leads to complex situations and difficulties in care decision making [3]. Triage level I resuscitation accounts for about $1.9 \sim 5 \%$ of all ED visits [4-7]. In previous studies conducted in Asia, the overall out-of-hospital cardiac arrest survival rates upon hospital discharge have ranged from 0.5 to $8.5 \%[8,9]$. The post-cardiac arrest resuscitation mean one-year survival rate was shown to be approximately $5 \%$ [10]. Many survivors experience neurological impairment [9] and further comorbidities can lead to long-term disability or initiate an end-of-life state, particularly for frail patients [11-14].

Early identification of the end-of-life state is key to avoiding low-value emergency care [15]. Medical service providers must make important decisions pertaining to resuscitation [16-18]. The Choosing Wisely Campaign (American College of Emergency Physicians) recommends that decision-makers begin palliative and hospice care in the ED [19]. The second set of the Choosing Wisely campaign also recommended that medical service providers engage with patients' shared decision making [20]. However, that a large number of patients who undergo triage level I resuscitation frequently miss opportunities for considering palliative care [13].

In January 2019, the Taiwan Ministry of Health and Welfare (MoHW) launched the Patient Autonomy Act, aimed at ensuring that all adults or surrogate(s) have access to counseling related to care options, including refusal of life-sustaining treatment for terminal diseases, irreversible comatose condition, vegetative state, advanced dementia, and other intractable illnesses or incurable diseases [21]. Medical decisions must account for clinical scenarios, previous experience making medical decisions, past experiences related to death and dying [22], and the social situation involving friends and family [23]. However, evidence-based post-resuscitation data for family meetings and discussion is still lacking. Therefore, this study compared resuscitation patients who received palliative care with those who received usual care in terms of medical utilization, medical expenses, and the provision of life-sustaining treatment. Our findings provide evidence that may extend palliative care to meet patients' need and reduce low-value care.

\section{Methods}

\section{Setting}

The National Health Insurance (NHI) program in Taiwan has provided hospice care since the first hospital-based hospice ward was opened in 1990, and palliative care since the Hospice Palliative Care Act was passed in 2000. The care settings include inpatient hospice wards and home and community hospice care. Palliative services were initially intended for patients with cancer or motor neuron diseases; however, it was expanded in 2009 to include eight categories of noncancer patients [24]. Since 2006, NHI IC cards have included a statement indicating a desire to receive palliative care as opposed to life-sustaining treatment. As of 2015 , approximately $15 \%$ of cardholders signed documents expressing their willingness to undergo palliative care [25]. In 2015, roughly 37,000 patients with a terminal illness received palliative care [25].

\section{Study design and data source}

This nationwide retrospective cohort study was based on the National Health Insurance Research Database (NHIRD) of Taiwan. We obtained NHIRD data from a sample of roughly one million nationally representative claims for inpatient and ambulatory care between September 1, 2009, to December 31, 2013 [26, 27]. The claim data included the date of ED; disease diagnoses based on the International Classification of Disease, Ninth Revision, Clinical Modification codes, laboratory workup, and medication. NHIRD was validated for accuracy in diagnostic coding [28], comorbidities [29], severity [30], and end-of-life state healthcare resource utilization [31].

\section{Ethics}

In accordance with regulations of the National Health Research Institutes, patient identification information was anonymized, such that informed consent was not required. This study was approved by the Institutional Review Board of Yang-Ming University (YM-107035E). No funding was received to support this research.

\section{Identification of study cohort}

Palliative care was extended to non-cancer patients in 2009; therefore, this study focused on the period between September 1, 2009, and December 31, 2013. Inclusion criteria included ED triage level I resuscitation during the study period. The palliative care sub-group included patients who received palliative care after posttriage level I resuscitation. Patients who received palliative care prior to the date of ED resuscitation were excluded. The date of the first palliative service was adopted as the index date. Patients in the palliative care subgroup were matched at a ratio of 1:4 with patients 
who received usual care in terms of event year, season, gender, age, and Charlson Comorbidity Index (CCI). Analysis was performed on the utilization of medical services from the index date until the patient died or the end of the study period. Cases were evaluated in terms of patient disposition, medical utilization, and medical outcomes.

\section{Variables}

The selection of outcome and control variables was based on a conceptual framework describing interventions specific to life-sustaining treatment [32]. The sociodemographic characteristics considered in this analysis included gender, age, occupation, and living area. The CCI was used to identify disease characteristics 1 year prior to the index date. Outcome variables included the number of visits to EDs and outpatient departments, the duration of hospitalization (in days), duration of survival after the index date (in days), total medical expenses, and life-sustaining treatments (including cardiopulmonary resuscitation, extracorporeal membrane oxygenation, hemodialysis, intensive unit care, intraaortic balloon pumping; mechanical ventilation, and nasogastric tube usage). These outcomes were derived from codes listed on inpatient claims.

\section{Statistical methods}

Baseline patient characteristics, medical utilization, and outcomes were compared between (1) the palliative group, and (2) usual care group. Differences in outcome variables were examined across gender, age, survival status, occupation, income, and CCI. ICD-9 codes for principal diagnoses, including palliative services-related codes from inpatient and outpatient NHI claims in the year prior to death, were used to identify comorbidities. The Deyo-Charlson comorbidity index was calculated using ICD-9 codes and categorized as 0,1 , or $\geqq 2$ comorbid conditions. Survival duration was based on the interval between the date of ED resuscitation and the date of death or research termination. Continuous variables and categorical variables were compared between groups using t-tests and the Chi-squared test, respectively. The distribution of covariates between groups was also assessed using Chi-square tests and t-tests, where a pvalue of $<0.05$ indicated a difference of statistical significance. Data with a skewed continuous distribution was described using the median and 25th and 75th percentiles (interquartile range). Kaplan-Meier survival analysis was used to analyze between-group differences related to survival, medical expenses, and the usage of lifesustaining treatments, in conjunction with the log-rank test to determine statistical significance. To obtain the contribution of each predictor to the overall explanatory power of the model, we conducted further subgroup analysis for each stratum of gender, age group, income, living area, CCI and occupation of palliative service and life-sustaining treatment using the full model without stratifying Multivariate logistic regression was used with one dichotomous dependent variable; i.e., whether or not life-sustaining treatment was implemented. Predictor variables included gender, age, income, living area, and CCI. Adjusted odds ratios with $95 \%$ confidence intervals were derived from logistic regression analysis, with statistical significance set at a $\mathrm{p}$-value $<0.05$ following

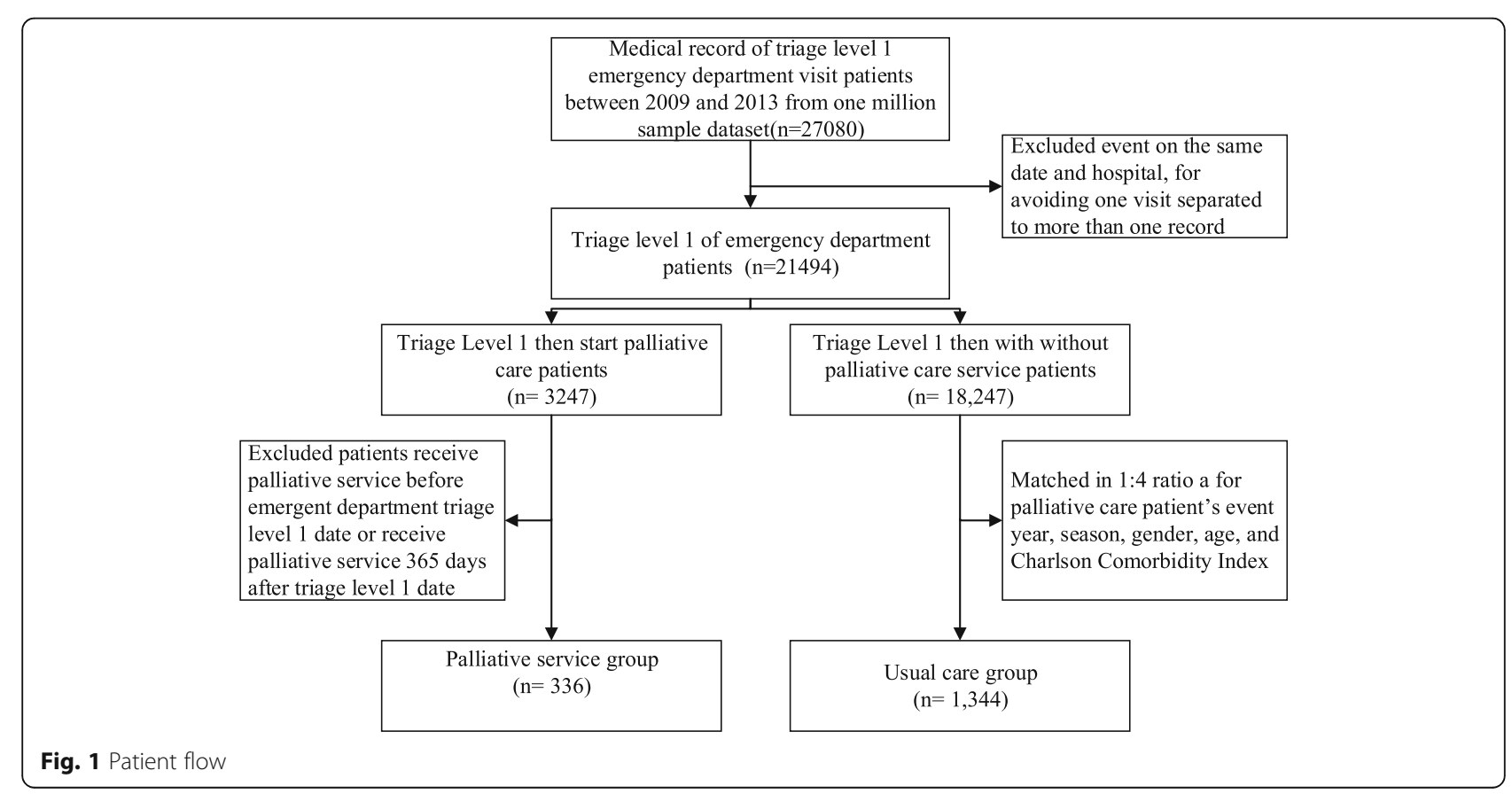


adjustment for risk factors. All analysis was performed using Statistical Analysis Software version 9.4 (SAS Institute Inc., Cary, NC, USA).

\section{Results}

\section{Baseline characteristics}

During this 5-year study period, we identified 21,494 cases of ED triage level I resuscitation, which included 336 subjects who received palliative services subsequent to resuscitation. In accordance with the Pitman efficiency index [33], those cases were matched with controls at a ratio of $1: 4 \quad(n=1344)$, resulting in a study cohort of 1680 resuscitation cases (Fig. 1). As shown in Fig. 1, the patients who received palliative care made up $15 \%$ of the entire ED triage level I resuscitation cohort. There were no significant differences between cases and controls in terms of sociodemographic variables, including gender, age, income, occupation, place of residence, or comorbidities (see Table 1). In the study cohort, the mean age was 70 years and $61.3 \%$ were male. The median insured salary was 880 USD per month, and more than $93 \%$ were $\mathrm{CCI}>1$. Most of the covariates remained comparable between the two groups throughout the follow-up period. Principal ED diagnoses were aggregated using single-level clinical classification software developed by the Agency for Healthcare Research [34]. ED discharge classifications in the palliative group were cancer-related diagnoses and organ-specific high impact time-sensitive conditions. In contrast, those in the usual care group included a variety of residual codes and organ-specific high impact time-sensitive conditions (Supplementary Table 1).

Table 1 Baseline demographics of all eligibles among the resuscitation patients with palliative care and usual care

\begin{tabular}{|c|c|c|c|c|c|c|c|c|c|c|}
\hline & \multicolumn{4}{|c|}{ Before Match } & \multirow[t]{4}{*}{$P$-value } & \multicolumn{4}{|c|}{ Post Match } & \multirow[t]{4}{*}{$P$-value } \\
\hline & \multirow{2}{*}{\multicolumn{2}{|c|}{$\begin{array}{l}\text { Palliative } \\
(n=346)\end{array}$}} & \multirow{2}{*}{\multicolumn{2}{|c|}{$\frac{\text { Usual care }}{(n=18,615)}$}} & & \multirow{2}{*}{\multicolumn{2}{|c|}{$\frac{\text { Palliative }}{(n=336)}$}} & \multirow{2}{*}{\multicolumn{2}{|c|}{$\begin{array}{l}\text { Usual care } \\
(n=1344)\end{array}$}} & \\
\hline & & & & & & & & & & \\
\hline & $\bar{n}$ & $(\%)$ & $\bar{n}$ & $\overline{(\%)}$ & & $n$ & $\overline{(\%)}$ & $n$ & $\overline{(\%)}$ & \\
\hline \multicolumn{11}{|l|}{ Sex } \\
\hline Female & 136 & 39.3 & 8081 & 43.4 & 0.13 & 130 & 38.7 & 520 & 38.7 & 0.99 \\
\hline Male & 210 & 60.7 & 10,534 & 56.6 & & 206 & 61.3 & 824 & 61.3 & \\
\hline \multicolumn{11}{|l|}{ Age } \\
\hline $18-64$ & 119 & 34.4 & 8465 & 45.5 & $<.0001$ & 110 & 32.7 & 448 & 33.3 & 0.84 \\
\hline$\geq 65$ & 227 & 65.6 & 10,150 & 54.5 & & 226 & 67.3 & 896 & 66.7 & \\
\hline \multicolumn{11}{|l|}{ Charlson Comorbidity Index } \\
\hline $\mathrm{CCl}=0$ & 5 & 1.4 & 5464 & 29.3 & $<.0001$ & 5 & 1.5 & 26 & 1.9 & 0.68 \\
\hline $\mathrm{CCl}=1$ & 14 & 4.1 & 3363 & 18.1 & & 14 & 4.2 & 68 & 5.1 & \\
\hline $\mathrm{CCl}>1$ & 327 & 94.5 & 9788 & 52.6 & & 317 & 94.3 & 1250 & 93 & \\
\hline \multicolumn{11}{|l|}{ Income level } \\
\hline Quintile 1 & 144 & 41.7 & 8408 & 45.2 & 0.269 & 140 & 41.7 & 614 & 45.7 & 0.11 \\
\hline Quintile 2 & 104 & 30.1 & 5587 & 30.0 & & 100 & 29.8 & 419 & 31.2 & \\
\hline Quintile 3 & 98 & 28.2 & 4620 & 24.8 & & 96 & 28.5 & 311 & 23.1 & \\
\hline \multicolumn{11}{|l|}{ Occupation } \\
\hline Dependents of the insured individuals & 134 & 38.7 & 6031 & 32.4 & 0.0006 & 132 & 39.3 & 493 & 36.7 & 0.92 \\
\hline $\begin{array}{l}\text { Civil servants, teachers, military } \\
\text { personnel, veterans }\end{array}$ & 37 & 10.7 & 1760 & 9.5 & & 37 & 11.0 & 152 & 11.3 & \\
\hline Nonmanual workers and professionals & 14 & 4.1 & 2065 & 11.1 & & 13 & 3.9 & 52 & 3.9 & \\
\hline Manual workers & 115 & 33.2 & 6132 & 33.0 & & 111 & 33.0 & 476 & 35.4 & \\
\hline Other & 46 & 13.3 & 2540 & 13.6 & & 43 & 12.8 & 168 & 12.5 & \\
\hline Missing & 0 & 0.0 & 87 & 0.4 & & 0 & 0.0 & 3 & 0.2 & \\
\hline \multicolumn{11}{|l|}{ Urbanization } \\
\hline Urban & 85 & 24.6 & 4735 & 25.4 & 0.1737 & 83 & 24.7 & 309 & 23.0 & 0.29 \\
\hline Suburban & 108 & 31.2 & 5077 & 27.3 & & 104 & 31.0 & 365 & 27.2 & \\
\hline Rural & 153 & 44.2 & 8666 & 46.6 & & 149 & 44.3 & 667 & 49.6 & \\
\hline Missing & 0 & 0.0 & 137 & 0.7 & & 0 & 0.0 & 3 & 0.2 & \\
\hline
\end{tabular}




\section{Medical expenses and utilization of life-sustaining treatment}

Table 2 lists data pertaining to duration of survival, medical expenses, and utilization of life-sustaining treatment in the palliative group and usual care group. The mean survival durations after resuscitation were as follows: palliative group (107.3 days) and usual care group (302.2 days). Compared with the palliative group, the usual care group included 5-fold more ED visits, 3-fold more hospitalizations, and 4-fold more ICU admissions. Compared with the palliative group, the usual care group had significantly higher medical expenses, hemodialysis, cardiopulmonary resuscitation, ventilator use, and life-sustaining treatment. No significant differences were observed between the two groups in terms of nasogastric tube feeding $(p=0.28)$.

\section{Life-sustaining treatments: predictors}

Multivariate analysis was used to examine various clinical factors of life-sustaining treatments administered after the index date (Table 3 ). The palliative group significantly exceeded the usual care group in terms of using nasogastric tube feeding (adjusted odds ratio $=$ 2.45 ; 95\% CI $1.87-3.20 ; p<.0001$ ). The usual care group significantly exceeded the palliative group in terms of hemodialysis usage (adjusted odds ratio $=0.39 ; 95 \% \mathrm{CI}$ $0.25-0.59 ; p<.0001)$, cardiopulmonary resuscitation usage (adjusted odds ratio $=0.24 ; 95 \%$ CI $0.15-0.38$; $p<.0001$ ), and ventilator usage (adjusted odds ratio $=$
0.42; 95\% CI 0.32-0.54; $p<.0001)$. Kaplan-Meier survival curves were significantly lower in the palliative group than in the usual care group (Log-rank test, $p<0.001$ ) (Fig. 2).

\section{Discussion}

Our results indicated that opting for palliative care was correlated with a shorter duration of life with disability, medical expenses, and life-sustaining treatment. Survival duration in the palliative group was significantly shorter than in the usual care group. Nonetheless, both groups qualified for end-of-life services (i.e., survival of less than 1 year) [35]. Note that patients in the palliative group made fewer visits to ED and outpatient departments, and were less likely to be hospitalized. Moreover, also that patients in the palliative group underwent fewer life-sustaining treatments and incurred fewer medical expenses.

\section{Methods discussion}

This study compared patients who did or did not undergo palliative care after successful ED resuscitation. Note that this methodology could be confounded by the indication for palliative services. Since 2009, Taiwan's NHI palliative care coverage expanded to eight noncancer irreversible advanced stage organ-system dysfunctions [24]. The NHI is tasked with providing comprehensive, low-cost healthcare [36] and highquality palliative care [37]. Taiwan expanded palliative

Table 2 Palliative care and usual care patients: survival, medical utilization and life-sustaining treatment use

\begin{tabular}{|c|c|c|c|c|c|}
\hline & \multicolumn{2}{|c|}{ Palliative care } & \multicolumn{2}{|c|}{ Usual care } & \multirow[t]{3}{*}{$p$-value } \\
\hline & \multicolumn{2}{|c|}{$(n=336)$} & \multicolumn{2}{|c|}{$(n=1344)$} & \\
\hline & Mean & (SD) & Mean & (SD) & \\
\hline Post ED resuscitation survival days & 107.3 & 127.20 & 302.2 & 406.70 & $<.0001$ \\
\hline Post palliative survival days & 48.7 & 81.87 & 273.8 & 384.90 & $<.0001$ \\
\hline ED visit & 0.4 & 1.11 & 2.1 & 6.12 & $<.0001$ \\
\hline Hospitalization & 0.5 & 1.36 & 1.6 & 3.10 & $<.0001$ \\
\hline ICU admission & 0.003 & 0.055 & 0.014 & 0.118 & 0.011 \\
\hline OPD expense (USD) & 256.2 & 776.1 & 4477.8 & $11,980.5$ & $<.0001$ \\
\hline Hospitalization expense (USD) & 1233.1 & 5089.0 & 5390.2 & $13,118.6$ & $<.0001$ \\
\hline All medical expense (USD) & 1489.3 & 5312.0 & 9898.1 & $19,572.0$ & $<.0001$ \\
\hline LST-Total LSTs usage & 9.0 & 21.20 & 22.2 & 62.35 & $<.0001$ \\
\hline LST-NGT feeding & 4.9 & 8.89 & 4.3 & 9.98 & 0.28 \\
\hline LST-IABP & - & - & 0.03 & 0.24 & - \\
\hline LST-ECMO & - & - & 0.02 & 0.20 & - \\
\hline LST-Hemodialysis & 1.9 & 12.61 & 13.5 & 56.94 & $<.0001$ \\
\hline LST-CPR & 0.1 & 0.27 & 0.2 & 0.46 & $<.0001$ \\
\hline LST-Ventilator & 2.1 & 6.79 & 4.1 & 14.58 & 0.0003 \\
\hline
\end{tabular}

$C P R$ Cardiopulmonary resuscitation, ECMO Extracorporeal membrane oxygenation, ED Emergency department, IABP Intraaortic balloon pumping, ICU Intensive care unit, LST Life-sustaining treatment, NGT Nasogastric tube, OPD Outpatient department, USD US Dollar, convert USD/TWD 1:30 


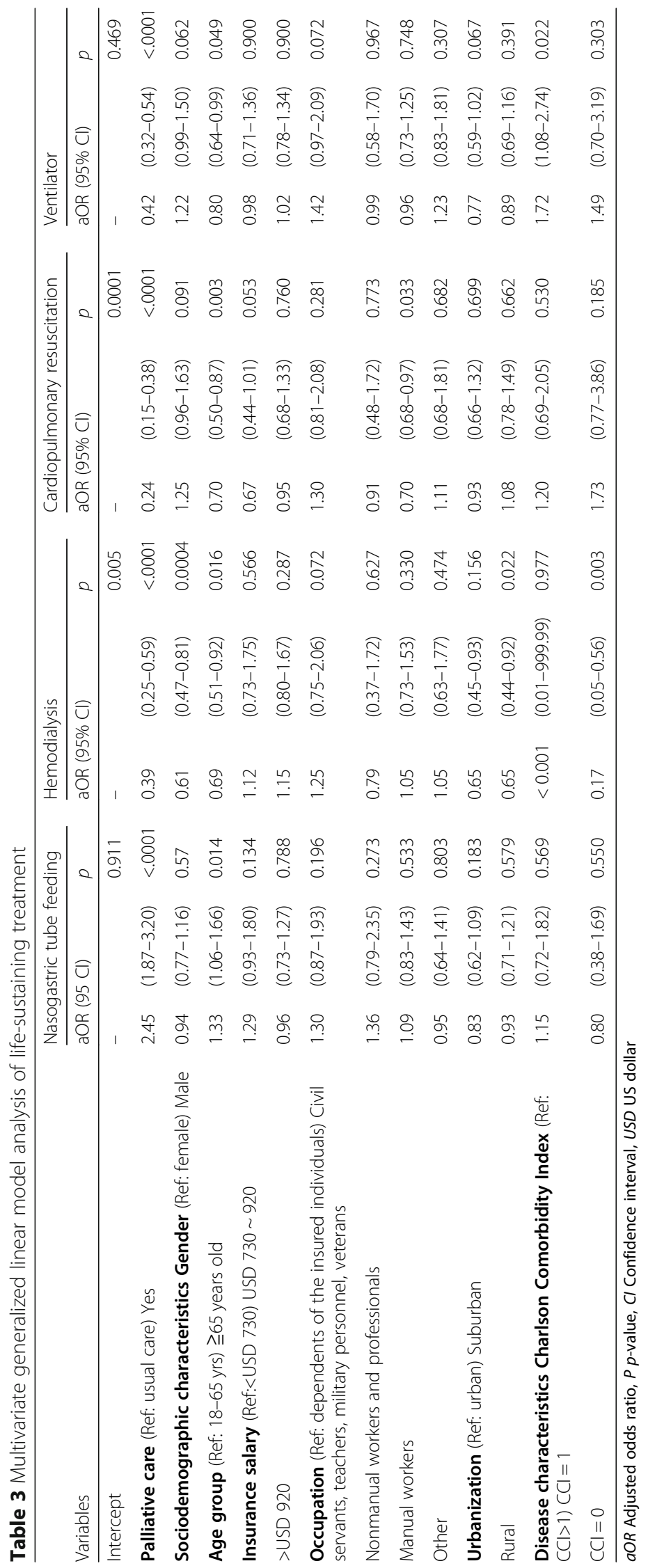




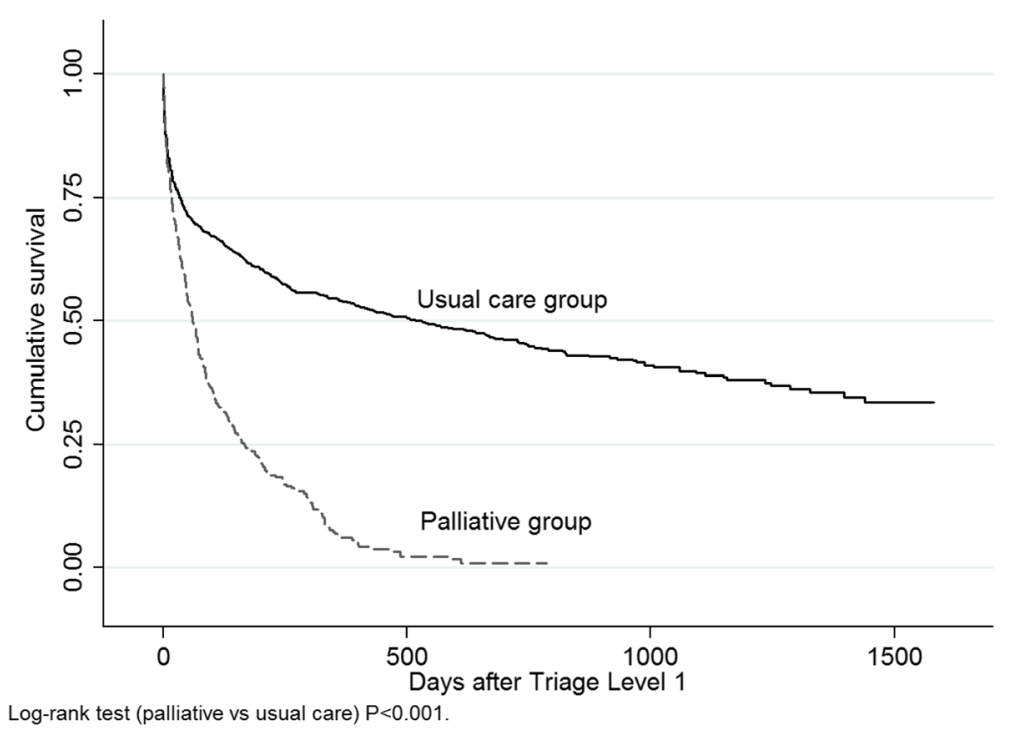

Fig. 2 Kaplan-Meier estimate plot for survival days post-emergency department resuscitation

care policy to reimburse full palliative care services, which increased access to cancer [38] and non-cancer palliative care in Taiwan [39]. Meanwhile, decisions pertaining to palliative care are affected by early palliative care consultation services [40], provider reimbursement policy [41], patient awareness of prognosis and completion of advances directives [42], and family awareness of diagnosis and prognosis [40]. It appears that healthcare utilization is determined largely by the fact that patients in the usual care group far outlived those in the palliative group post-resuscitation. The greater use of medical utilization and life-sustaining treatment is most likely due to the longer post-resuscitation survival in the usual care group. Compared to the usual care group, the palliative group had a shorter survival duration and less extensive utilization of life-sustaining treatments. Our primary objective in this paper was to promote conversation pertaining to palliative care between patients and medical practitioners in order to identify suitable candidates for palliative care and thereby prevent unnecessary suffering.

\section{Results discussion}

Contemporary palliative care practice and research are disease-oriented (cancer and non-cancer disease) [43, 44] and setting-oriented (palliative ward, ED, intensive care unit, home-based, long-term care facility, and community-based setting) approaches [45-48]. ED level I resuscitation is a common pathway of patients with advanced and progressive deterioration illnesses, as well as those with incurable frailty or co-existing conditions. In this study, the post-ED resuscitation survival duration of all patients (both groups) was 351 days, which clearly falls within the definition of palliative care [35]. In cases where the patient is in an incurable or severely disabled state post-resuscitation, palliative care should be considered. It has been estimated that total health expenditures could be reduced by $30 \%$ simply by avoiding repeated visits to the ED or unnecessary ICU hospitalization during the final months of life [49-51]. Our results indicate that decisions pertaining to palliative care could be considered earlier to reduce suffering and decrease expenses for low-value medical care $[49,52,53]$. Paradoxically, tube feeding was higher in the palliative care group; however, this has also been reported in previous studies conducted in Asia [54, 55]. Many Asians believe that providing artificial nutrition is necessary to prevent dying patients from becoming what is referred to as 'hungry ghosts' [56, 57].

This study has a number of limitations. First, the patients included in the palliative group were not selected at random. Nonetheless, claims data from the NHIRD is representative of critical care in Taiwan with respect to ED size, location, academic affiliation, and patient characteristics. Second, we were unable to determine the reasons underlying the assignment of participants to palliative care. Moreover, we were unable to measure the number of palliative care patients who received life-sustaining treatment or the corresponding timelines. Third, this study did not have access to data related to sociocultural factors, the nature of each case, personal medical experience, or family dynamics.

\section{Conclusions}

The implementation of palliative care was correlated with fewer life-sustaining treatments following resuscitation. This study provides real-world data pertaining to 
post-resuscitation care, which could be of value to clinicians, patients, and their families undergoing with evidence-based counseling when facing life-sustaining treatment share decision making. We believe that ED triage level I resuscitation status is a potential starting point for early palliative case finding and end-of-life counseling.

\section{Supplementary information}

Supplementary information accompanies this paper at https://doi.org/10. 1186/s12904-020-00590-5.

Additional file 1: Supplementary Table 1. Top 20 categories of single-level clinical classifications: Palliative and usual care groups

\section{Abbreviations}

CCl: Charlson Comorbidity Index; CPR: Cardiopulmonary resuscitation; ECMO: Extracorporeal membrane oxygenation; ED: Emergency department; IABP: Intraaortic balloon pumping; ICU: Intensive care unit; MoHW: Ministry of Health and Welfare; NHI: National Health Insurance; NGT: Nasogastric tube; NHIRD: National Health Insurance Research Database; OPD: Outpatient department; USD: US Dollar

\section{Acknowledgments}

We acknowledge the Taiwan National Health Insurance Research Database, which was provided by the National Health Insurance Administration, and is managed by National Health Research Institutes.

\section{Authors' contributions}

C-Y.L. study concept and design, analysis and interpretation of data, preparation of the manuscript. Y-C.L. supervision for the development of study concept and design, analysis and interpretation of data, preparation of the manuscript. The authors have read and approved the manuscript

\section{Funding}

The authors declare that they have no funding.

\section{Availability of data and materials}

The data that support the findings of this study are available from Taiwan National Health Insurance Research Database but restrictions apply to the availability of these data, which were used under license for the current study, and so are not publicly available. Data are however available from the academic request and with permission of Taiwan National Health Insurance Administration.

\section{Ethics approval and consent to participate}

This study approved by Institutional Review Board of National Yang-Ming University-YM107035E on May, 5 2018. In accordance with regulations of the National Health Research Institutes, patient identification information was anonymized, such that informed consent was not required.

\section{Consent for publication}

Not applicable.

\section{Competing interests}

The authors declare that they have no competing interests.

\section{Author details}

'Department of Neurology, Taipei City Hospital, Taipei, Taiwan. ${ }^{2}$ Institute of Health and Welfare Policy, School of Medicine, National Yang-Ming University, Taipei, Taiwan. ${ }^{3}$ Department of Health Care Management, National Taipei University of Nursing and Health, Taipei, Taiwan. ${ }^{4}$ Master Program on Trans-disciplinary Long-Term Care and Management, National Yang-Ming University, Taipei, Taiwan.
Received: 14 March 2020 Accepted: 9 June 2020

Published online: 20 June 2020

\section{References}

1. Fernandes $C M$, et al. Five-level triage: a report from the ACEP/ENA five-level triage task force. J Emerg Nurs. 2005;31(1):39-50.

2. Hinson JS, Martinez DA, Cabral S, et al. Triage performance in emergency medicine: a systematic review. Ann Emerg Med. 2019;74(1):140-52.

3. Meeker MA, Jezewski MA. Metasynthesis: withdrawing life-sustaining treatments: the experience of family decision-makers. J Clin Nurs. 2009;18(2): 163-73.

4. Baumann MR, Strout TD. Triage of geriatric patients in the emergency department: validity and survival with the emergency severity index. Ann Emerg Med. 2007;49(2):234-40.

5. Raita $Y$, et al. Emergency department triage prediction of clinical outcomes using machine learning models. Crit Care. 2019;23(1):64.

6. Dugas AF, et al. An electronic emergency triage system to improve patient distribution by critical outcomes. J Emerg Med. 2016;50(6):910-8.

7. Lin $Y C$, et al. Emergency department utilization and resuscitation rate among patients receiving maintenance hemodialysis. J Formos Med Assoc. 2019

8. Nichol G, et al. Post-discharge outcomes after resuscitation from out-ofhospital cardiac arrest: a ROC PRIMED substudy. Resuscitation. 2015:93:74-81.

9. Ong ME, et al. Outcomes for out-of-hospital cardiac arrests across 7 countries in Asia: the pan Asian resuscitation outcomes study (PAROS). Resuscitation. 2015;96:100-8.

10. Su CP, et al. Demographics and clinical features of Postresuscitation comorbidities in long-term survivors of out-of-hospital cardiac arrest: a National Follow-up Study. Biomed Res Int. 2017;2017:9259182.

11. Huang $\mathrm{C}-\mathrm{H}$, et al. Factors influencing the outcomes after in-hospital resuscitation in Taiwan. Resuscitation. 2002:53(3):265-70.

12. Ebell MH, Afonso AM. Pre-arrest predictors of failure to survive after inhospital cardiopulmonary resuscitation: a meta-analysis. Fam Pract. 2011 28(5):505-15.

13. Mogul AS, et al. Missed opportunities: integrating palliative care into the emergency Department for Older Adults Presenting as level I triage priority from long-term care facilities. J Emerg Med. 2019;56(2):145-52.

14. Zafar W, et al. Outcomes of in-hospital cardiopulmonary resuscitation among patients with cancer: experience from Pakistan. Am J Hosp Palliat Med. 2017:34(3):212-6.

15. Blanch $L$, et al. Triage decisions for ICU admission: report from the task force of the world Federation of Societies of intensive and critical care medicine. J Crit Care. 2016:36:301-5.

16. Eddy DM. Clinical Decision Making: From Theory to Practice : a Collection of Essays from JAMA. Boston: Jones and Bartlett Publishers; 1996.

17. Somers AR, Somers HM. A proposed framework for health and health care policies. Inquiry. 1977:14(2):115-70.

18. Smithline HA, Mader TJ, Crenshaw BJ. Do patients with acute medical conditions have the capacity to give informed consent for emergency medicine research? Acad Emerg Med. 1999;6(8):776-80.

19. Choosing Wisely Champions. American College of Emergency Physicians: Ten Things Physicians and Patients Should Question. October 14, 2013 (1-5) and October 27, 2014 (6-10) [cited 2019 February 20]; Available from: http:// www.choosingwisely.org/societies/american-college-of-emergencyphysicians/.

20. American College of Emergency Physicians. Choosing Wisely Champions 2018; 2018. [cited 2019 February 20]; Available from: https://www.acep.org/ choosingwiselychampions/\#sm.00001 mbr3ca40ecnyoy2lwbd5u2fy.

21. Department of Health and Welfare. Patient autonomy act; 2019. [cited 2019 January, 12]; Available from: https://zh.wikipedia.org/wiki/\%E7\%97\%85\%E4\% BA\%BA\%E8\%87\%AA\%E4\%B8\%BB\%E6\%AC\%8A\%E5\%88\%A9\%E6\%B3\%95.

22. McMahan $\mathrm{RD}$, et al. Advance care planning beyond advance directives: perspectives from patients and surrogates. J Pain Symptom Manage. 2013; 46(3):355-65.

23. Kahana $B$, et al. The personal and social context of planning for end-of-life care. J Am Geriatr Soc. 2004:52(7):1163-7.

24. National Health Insurance Administration. National Health Insurance Medical Service Payment Items and payment standards; 2019. [cited 2019 February 12]; Available from: https://www.nhi.gov.tw/Default.aspx. 
25. Ministry of Health and Welfare. Taiwan health and welfare report 2017. Taiwan: Ministry of Health and Welfare; 2017.

26. Lin LY, et al. Data resource profile: the National Health Insurance Research Database (NHIRD). Epidemiol Health. 2018;40:e2018062.

27. Hsieh CY, et al. Taiwan's National Health Insurance Research Database: past and future. Clin Epidemiol. 2019;11:349-58.

28. Ho TW, et al. Validity of ICD9-CM codes to diagnose chronic obstructive pulmonary disease from National Health Insurance claim data in Taiwan. Int J Chron Obstruct Pulmon Dis. 2018;13:3055-63.

29. Yang CC, et al. Validity of the age-adjusted charlson comorbidity index on clinical outcomes for patients with nasopharyngeal cancer post radiation treatment: a 5-year nationwide cohort study. PLoS One. 2015;10(1): e0117323.

30. Hung LC, et al. Validation of a novel claims-based stroke severity index in patients with intracerebral hemorrhage. J Epidemiol. 2017;27(1):24-9.

31. Kuo LC, et al. End-of-life health care utilization between chronic obstructive pulmonary disease and lung cancer patients. J Pain Symptom Manage. 2019.

32. In Der Schmitten J, et al. Patient advance directives in the emergency medical service setting (part 2): new perspectives through advance care planning and the physician orders for life-sustaining treatment. Notfall und Rettungsmedizin. 2011;14(6):465-74.

33. Armitage PC, Theodore, Zacks S. Pitman efficiency. In: Encyclopedia of biostatistics; 2005. p. 73.

34. Cost, H. and U. Project, Clinical classifications software (CCS) for ICD-9-CM. Available at: www.hcup-us.ahrq.gov/toolssoftware/ccs/ccs.jsp. Accessed February, 2018. 27.

35. Thomas. K et al. Prognostic Indicator Guidance (PIG) 4th Edition-The National GSF Centre's guidance for clinicians to support earlier recognitionof patients nearing the end of life. Shrewsbury: The Gold Standards Framework Centre In End of Life Care CIC; 2011.

36. Wu T-Y, Majeed A, Kuo KN. An overview of the healthcare system in Taiwan. London J Primary Care. 2010;3(2):115-9.

37. Cheng S-Y, Chen C-Y, Chiu T-Y. Advances of hospice palliative care in Taiwan. Korean J Hospice Palliative Care. 2016;19(4):292-5.

38. Shao YY, et al. National policies fostering hospice care increased hospice utilization and reduced the invasiveness of end-of-life Care for Cancer Patients. Oncologist. 2017;22(7):843-9.

39. Kang SC, et al. Noncancer hospice care in Taiwan: a nationwide dataset analysis from 2005 to 2010. J Palliat Med. 2014;17(4):407-14.

40. Kao CY, et al. Predictive factors for do-not-resuscitate designation among terminally ill cancer patients receiving care from a palliative care consultation service. J Pain Symptom Manage. 2014;47(2):271-82.

41. Chen $B$, et al. Reducing costs at the end of life through provider incentives for hospice care: a retrospective cohort study. Palliat Med. 2018;32(8):1389-400.

42. Yen YF, et al. Association of Advance Directives Completion with the utilization of life-sustaining treatments during the end-of-life Care in Older Patients. J Pain Symptom Manage. 2018;55(2):265-71.

43. Franks PJ, et al. The level of need for palliative care: a systematic review of the literature. Palliat Med. 2000;14(2):93-104.

44. Van Lancker A, et al. A comparison of symptoms in older hospitalised cancer and non-cancer patients in need of palliative care: a secondary analysis of two cross-sectional studies. BMC Geriatr. 2018;18(1):40.

45. Stiel S, et al. Symptoms and problem clusters in cancer and non-cancer patients in specialized palliative care-is there a difference? I Pain Symptom Manage. 2014:48(1):26-35.

46. Afshar K, et al. Generalist palliative care for non-cancer patients : a review article. Schmerz. 2016.

47. Spilsbury K, Rosenwax L. Community-based specialist palliative care is associated with reduced hospital costs for people with non-cancer conditions during the last year of life. BMC Palliat Care. 2017;16(1):68.

48. Hepgul $\mathrm{N}$, et al. Integrating palliative care into neurology services: what do the professionals say? BMJ Support Palliat Care. 2018;8(1):41-4.

49. Cardona-Morrell $M$, et al. Non-beneficial treatments in hospital at the end of life: a systematic review on extent of the problem. International J Qual Health Care. 2016.

50. Combes J, Arespacochaga E. Appropriate use of medical resources; 2013. American Hospital Association, Physician Leadership Forum.

51. Organisation for Economic Co-operation and Development. Tackling wasteful spending on health. Paris: OECD Publishing; 2017. https://doi.org/ 10.1787/9789264266414-en.
52. Kang SC, et al. The impact of hemodialysis on terminal cancer patients in hospices: a Nationwide retrospective study in Taiwan. J Palliat Med. 2019; 22(2):188-92.

53. Ahmad AS, et al. Outcomes of cardiopulmonary resuscitation and estimation of healthcare costs in potential 'Do not Resuscitate' cases. Sultan Qaboos Univ Med J. 2016;16(1):e27-34.

54. Chen PJ, et al. Association between palliative care and life-sustaining treatments for patients with dementia: a nationwide 5-year cohort study. Palliat Med. 2018;32(3):622-30.

55. Clarfield AM, et al. Enteral feeding in end-stage dementia: a comparison of religious, ethnic, and national differences in Canada and Israel. J Gerontol Ser A Biol Med Sci. 2006;61(6):621-7.

56. Rifkin DE. Feeding the hungry ghosts. Am J Kidney Dis. 2010;55(1):A33-4.

57. Tang ST, et al. A decade of changes in preferences for life-sustaining treatments among terminally ill patients with cancer. J Natl Compr Canc Netw. 2015;13(12):1510-8.

\section{Publisher's Note}

Springer Nature remains neutral with regard to jurisdictional claims in published maps and institutional affiliations.
Ready to submit your research? Choose BMC and benefit from:

- fast, convenient online submission

- thorough peer review by experienced researchers in your field

- rapid publication on acceptance

- support for research data, including large and complex data types

- gold Open Access which fosters wider collaboration and increased citations

- maximum visibility for your research: over $100 \mathrm{M}$ website views per year

At $\mathrm{BMC}$, research is always in progress.

Learn more biomedcentral.com/submissions 